\title{
A Comparative Evaluation of Intrathecal Levobupivacaine with Dexmedetomidine versus Levobupivacaine in Gynecological Surgeries.
}

\author{
Tiwari J.P ${ }^{1}$, Tripathi D.K ${ }^{2}$, Bhaskar $\mathrm{P}^{3}$, Negi D. $\mathrm{S}^{4}$, Dr.Vishal Mishra ${ }^{5}$, \\ Dr. Prashant Rai ${ }^{5}$, Dr.Mohd.Chand ${ }^{5}$, Dr Puja Chovatiya ${ }^{5}$, \\ Dr Mohit Mangal $^{5}$, Prof. Sheela Misra ${ }^{6}$, Anjali Singh ${ }^{7}$ \\ 1,2,3,4,5 Department Of Anaesthesiology Ram Manohar Lohia Combined Hospital Lucknow U.P India \\ ${ }^{6}$ Prof. Department of Statistics, University Of Lucknow, \\ ${ }_{7}$ Research Scholar Department of Statistics, University Of Lucknow
}

\begin{abstract}
Pain is the most distressing aspect of any type of surgery. Analgesic multimodalities have been used but are fragile with side effects that limit their usefulness. In this prospective randomized double blind study we have evaluated the anesthetic efficacy and safety of addition of $5 \mu \mathrm{gm}$ dexmedetomidine to $15 \mathrm{mg}$ isobaric levobupivacaine in patients undergoing elective gynecological surgeries regarding time of onset, level of sensory block, intensity of motor block, duration of analgesia, haemodynamic stability and any complications. Eighty ASA I \& II female patients, 30-60 yrs age scheduled for elective gynecological surgery under spinal anesthesia were divided into two groups. Patients were randomly allocated to receive either $3 \mathrm{ml}$ isobaric levobupivacaine $5 \mathrm{mg} / \mathrm{ml}(15 \mathrm{mg}$ ) with $5 \mu \mathrm{gm}$ dexmedetomidine ( group $D, n=40$ ), or $3 \mathrm{ml}$ isobaric levobupivacaine $5 \mathrm{mg} / \mathrm{ml}(15 \mathrm{mg}$ ) with $0.5 \mathrm{ml}$ normal saline (group $S, n=40$ ) .Time of onset \&maximum upper level of sensory block was assessed by Pin prick test, Intensity of motor block by modified Bromage scale and duration of analgesia by VAS (visual analogue scale) were recorded as were any side effects such as sedation, bradycardia, hypotention, hypoxia, nausea, vomiting, shivering and respiratory depression. In group D there was faster onset of sensory block with more intensified motor block but haemodynamicaly less stable compared to group S. Levobupivacaine-dexmedetomidine combination required less top up analgesics postoperatively with minimal side effects compared to levobupivacaine-normal saline combination. Thus overall combined effect of intrathecal levobupivacaine and dexmedetomidine is superior over levobupivacaine alone.
\end{abstract}

Keywords; Levobupivacaine,Dexmedetomidinel,Regional anesthesia,Anesthetics techniques.

\section{Introduction}

Pain is the most distressing aspect of any type of surgery. Analgesic multimodalities have been used but are fragile with side effects that limit their usefulness. Spinal anesthesia is preferred method for lower abdominal and lower limb surgery being simple to perform ,economical providing a fast onset and effective sensory and motor blockade However local anesthetics when used alone is associated with relatively short duration of action, thus early analgesic intervention is needed in the postoperative period . Bupivacaine is available as a racemic mixture of its enantiomers, dextrobupivacaine, and levobupivacaine. In the past few years, its pure S-enantiomers ropivacaine and levobupivacaine have been introduced into clinical practice ${ }^{1-4 .}$ because of their lower toxic effects for cardiovascular and central nervous system. The clinical profile of spinal bupivacaine and levobupivacaine has been evaluated in volunteers and found to be effective in patients undergoing lower abdomen surgery,

day care gynecology procedures, inguinal hernia repair, and

lower limb procedures ${ }^{5}-16$.

In the current study the aim is to evaluate the role of dexmedetomidine when added to isobaric levobupivacaine $0.5 \%$ intrathecally among patients subjected to gynecological surgeries.

Although there are studies in the literature regarding lower abdominal surgeries under spinal anesthesia comparing local anesthetics and various adjuvants like opioids, clonidine \& dexmedetomedine. Most of the clinical studies about the intrathecal $\alpha_{2}$ adrenergic agonist are related to clonidine ${ }^{31}$. Highly selective $\alpha_{2}$ adrenergic agonist dexmedetomidine is emerging as new adjunct to regional anesthesia ,analgesia and critical care setting ${ }^{32}$. Gradually evolving studies can build the evidence for its safe use in central neuraxial block ${ }^{33}$. On the basis of previous studies it is hypothesized that intrathecal $5 \mu \mathrm{gm}$ dexmedetomidine would produce more post operative analgesic effect with hyperbaric bupivacaine in spinal anesthesia with minimal side effects ${ }^{27-30}$. In this prospective randomized double blind controlled study our aim was to compare the effect of addition of dexmedetomidine to levobupivacaine on anesthesia quality, time of 
onset of sensory and motor block, intensity of motor block, duration of analgesia ,haemodynamic stability and any side effects.

\section{Material \& Methods}

After approval of ethics committee a written informed consent was taken. This prospective double blind, randomized study was conducted at Ram Manohar Lohia Combined Hospital, Lucknow . Eighty patients of ASA I \& II, 20 to 60 yrs of age, female patients undergoing elective Gynecological surgeries under spinal anasthesia were included in the study. The patients were randomly allocated into 2 groups ; Group D ( $n=40)$ received intrathecal isobaric Levobupivacaine $3 \mathrm{ml}, 0.5 \%(5 \mathrm{mg} / \mathrm{ml})$ with $5 \mu \mathrm{g}$ Dexmedetomidine $(0.5 \mathrm{ml})$ (total $3.5 \mathrm{ml}$ ) and group $\mathrm{S}(\mathrm{n}=40)$ received intrathecal isobaric Levobupivacaine $3 \mathrm{ml}, 0.5 \% \quad(5 \mathrm{mg} / \mathrm{ml})$ with normal saline $0.5 \mathrm{~m}$ (Total $3.5 \mathrm{ml}$ ).

Exclusion criteria : Patients with known history of allergy to drug, any contraindication to spinal anesthesia, emergency surgery, patients not willing to participate in the study, hepatic and renal insufficiency.

Study Procedure: After the standard monitors were placed, intravenous access was established \& patients were preloaded with $10 \mathrm{ml} / \mathrm{kg}$ Lactated Ringers solution over 20 minute prior to surgery. Spinal anesthesia was performed with $25 \mathrm{G}$ Quincke spinal needle at $\mathrm{L}_{3-4}$ intervertebral space with patient in the sitting position using midline approach after confirming free flow of clear cerebrospinal fluid. Depending on the study group the injection of anesthetic solution (total $3.5 \mathrm{ml}$ ) with cephalic orientation of spinal needle aperture was administered over 10-15 seconds The spinal needle was removed \& the patient was placed in supine position .The end of injection was defined as time zero.

Noninvasive monitoring of vitals (ECG, Pulse Oximetry, heart rate, blood pressure, respiratory rate) were performed in operation theatre. Time of onset and highest level of sensory block was evaluated by pinprick method using $22 \mathrm{G}$ hypodermic needle. The highest level of sensory block was evaluated by pinprick at midclavicular line. Modified Bromage Scale was used to evaluate motor block. Vitals were recorded at preoperatively \& then at $5 \mathrm{~min}, 15 \mathrm{~min}, 30 \mathrm{~min}, 60 \mathrm{~min}, 120 \mathrm{~min}$ interval and then every half an hour till complete recovery. Duration of analgesia was assessed by time of administration of first injection of analgesic in the postoperative period. Need for analgesic injection was assessed by VAS. Patients satisfaction was assessed by interviewing them postoperatively wether they would like to have similar anesthesia in future if required. Incidence of hypotention ,bradycardia, respiratory depresion, nausea, vomiting, shivering,, backache, headache and urinary retention were also recorded .

Hypotension (fall $\geq 20 \%$ of baseline MAP) was treated with $5 \mathrm{mg}$ increments of injection ephedrine i.v. and intravenous fluids. Criteria fof resp piratory depression was respiratory rate $\leq 8 \mathrm{bpm}$ and oxygen saturation $<92 \%$ on room air. Intra and postoperative pain was assessed on visual analogue scale (VAS: a horizontal 0 to 10 c.m. straight line with left of the line expressing no pain and the right end of line the worst pain). Duration of analgesia was scored when first rescue analgesic was required postoperatively. De Kock sedation scale was used: $1=$ patient somnolent but responding to verbal commands;2=patient somnolent , not responding to verbal command; 3 =patient somnolent; not responding to verbal command or manual stimulation.

\section{Results}

Results were expressed by standard methods as mean + standard deviation. Chi-square test was applied for demographic data and haemodynamic parameters. Data obtained were tabulated and analyzed using Statistical Package for Social Science (SPSS 20.0 evaluation version). P-value was considered significant if $<0.05$ and highly significant if $<0.001$. All patients $(n=80)$ completed the study; there was no statistical difference in patients demographics or duration of surgery as shown in( Table 1) shows the number of patients in each group undergoing different type of gynecological surgeries.

There was no significant difference between the study groups regarding mean age, weight, height, sex ratio and duration of surgery .

Table 1: Comparison of Demographic Data in Two Groups

\begin{tabular}{|c|c|c|c|c|c|c|}
\hline & \multicolumn{2}{|c|}{ Group D $(n=40)$} & \multicolumn{2}{|c|}{ Group S $(n=40)$} & \multirow[t]{2}{*}{ "t $t "$} & \multirow[t]{2}{*}{ "p" } \\
\hline & Mean & SD & Mean & SD & & \\
\hline Age( in years) & 49.13 & 7.208 & 49.00 & 10.033 & 0.064 & 0.949 \\
\hline Weight (in kg) & 59.38 & 6.724 & 58.48 & 5.344 & 0.663 & 0.509 \\
\hline Height ( in $\mathrm{cm}$ ) & 158.80 & 6.001 & 159.03 & 5.166 & -0.180 & 0.858 \\
\hline $\begin{array}{l}\text { Haemoglobin } \\
(\mathrm{gm} / \mathrm{dl})\end{array}$ & 11.30 & 0.758 & 11.30 & 0.853 & 0.000 & 1.000 \\
\hline $\begin{array}{l}\text { ASA Grade } \\
\text { I } \\
\text { II }\end{array}$ & $\begin{array}{l}37(92.5 \%) \\
3(7.5 \%)\end{array}$ & & $\begin{array}{l}33(82.5 \\
7(17.5\end{array}$ & & 0.000 & 1.000 \\
\hline
\end{tabular}


Group D showed better heart rate control throughout surgery compared to Group S. There was gradual fall in mean heart rate in group D at 10 min after subarachnoid block which came to baseline in 60 min which was not statistically significant $(\mathrm{p}<0.05)$ but in group $\mathrm{S}$ there remained a significant difference in intraoperative mean heart rate compared to baseline mean heart rate.

Table 2: Comparison of Heart Rate (bmp) in two groups at different time intervals

\begin{tabular}{|c|c|c|c|c|c|c|}
\hline \multirow[b]{2}{*}{ Time } & \multicolumn{2}{|c|}{ Group D $(n=40)$} & \multicolumn{2}{|c|}{ Group $S(n=40)$} & \multirow[b]{2}{*}{ " $t$ " } & \multirow[b]{2}{*}{ “p” } \\
\hline & Mean & SD & Mean & SD & & \\
\hline Pre OP & 87.68 & 6.451 & 83.73 & 7.633 & 2.500 & 0.015 \\
\hline $5 \mathrm{~min}$ & 85.10 & 6.916 & 83.25 & 7.292 & 1.164 & 0.248 \\
\hline $10 \mathrm{~min}$ & 81.50 & 7.345 & 82.90 & 5.956 & -0.936 & 0.352 \\
\hline $15 \mathrm{~min}$ & 76.43 & 6.555 & 83.28 & 4.723 & -5.362 & 0.000 \\
\hline $30 \mathrm{~min}$ & 74.80 & 4.842 & 82.73 & 4.466 & -7.609 & 0.000 \\
\hline $60 \mathrm{~min}$ & 70.38 & 5.687 & 81.33 & 3.619 & -10.274 & 0.000 \\
\hline $120 \mathrm{~min}$ & 66.25 & 4.866 & 80.15 & 3.527 & -14.628 & 0.000 \\
\hline
\end{tabular}

Hypotention was observe in 7 (17.5\%) patients in group D while it was seen in only $3(7.5 \%)$ patients in group S.As compared to preoperative value there was fall in MAP in both the groups but there was less fall in MAP in group $\mathrm{S}$ compared to $\mathrm{D}$ thus patients receiving intrathecal dexmedetomidin were hemodynamically less stable.

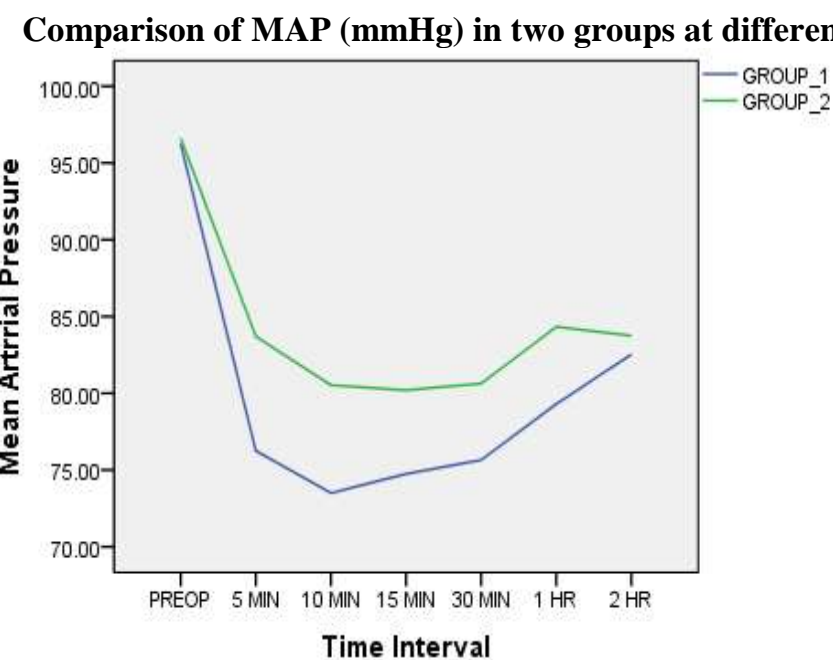

Mean time of onset of sensory block was faster in group D (4.65+0.976 min ) than group S $(6.475 \pm$

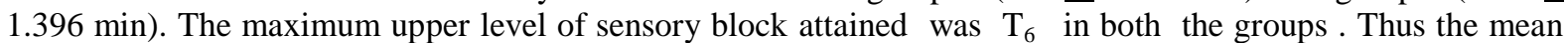
value of upper level of sensory was comparable in both the groups.

Time of Onset and Highest level of Sensory Block

\begin{tabular}{|c|c|c|c|c|c|c|c|c|}
\hline \multirow{2}{*}{\multicolumn{2}{|c|}{$\begin{array}{l}\text { Upper Level of Sensory } \\
\text { Block }\end{array}$}} & \multicolumn{7}{|c|}{ Time of onset sensory block } \\
\hline & & $4 \mathrm{~min}$ & $6 \mathrm{~min}$ & $8 \mathrm{~min}$ & $10 \mathrm{~min}$ & Total & $\mathrm{t}$ value & $\mathrm{p}$ value \\
\hline \multirow[t]{2}{*}{$\mathrm{T}_{6}$} & Group D & 9 & 8 & 0 & 0 & 17 & \multirow[t]{7}{*}{-6.77625} & \multirow[t]{7}{*}{$\mathrm{P}<0.001$} \\
\hline & Group S & 0 & 6 & 8 & 1 & 15 & & \\
\hline \multirow[t]{2}{*}{$\mathrm{T}_{8}$} & Group D & 8 & 11 & 1 & 0 & 20 & & \\
\hline & Group S & 2 & 11 & 7 & 2 & 22 & & \\
\hline \multirow[t]{2}{*}{$\mathrm{T}_{10}$} & Group D & 0 & 3 & 0 & 0 & 3 & & \\
\hline & Group S & 1 & 2 & 0 & 0 & 3 & & \\
\hline \multirow{2}{*}{$\begin{array}{l}\text { Mean onset } \\
\text { time }\end{array}$} & Group D & \multicolumn{4}{|c|}{$4.65 \pm 0.976$} & 80 & & \\
\hline & Group S & \multicolumn{4}{|c|}{$6.475 \pm 1.396$} & & & \\
\hline
\end{tabular}

In group D Grade 3 motor blockede (Modified Bromage Scale) was seen in 37 patients $(\mathrm{n}=37 / 40)$ $(92.5 \%)$ and grade 2 in 3 patients $(n=3 / 40)(7.5 \%)$. In group S 32 patients showed grade 3 motor blockade (80\%), 6 patients (15\%) grade 2 and 2 patients (5\%) grade 1 motor blockade thus it was found that group D had more intensified motor block compared to group $\mathrm{S}(\mathrm{p}=0.64432)$. 
Intensity of Motor Blockade

\begin{tabular}{|c|c|c|c|c|}
\hline Motor Blockade & Group $\mathrm{D}(\mathrm{n}=40)$ & Group $S(n=40)$ & Chi Square & $\mathrm{p}$ value \\
\hline $\mathrm{I}$ & 0 & 2 & \multirow[t]{6}{*}{3.36232} & \multirow[t]{6}{*}{0.64432} \\
\hline II & 3 & 6 & & \\
\hline III & 37 & 32 & & \\
\hline IV & 0 & 0 & & \\
\hline & 0 & 0 & & \\
\hline $\mathrm{VI}$ & 0 & 0 & & \\
\hline
\end{tabular}

Mean duration of analgesia in group D was $9.35(9.35+3.635) \mathrm{hrs}$ while in group $\mathrm{S}$ it was $3.634+1.347)$ hrs. min. Duration of analgesia was significantly prolonged in group D than group $S$ and also less top up analgesics were required in postoperative period in group D thus making it cost effective.

\begin{tabular}{|l|l|l|l|l|l|l|}
\hline & \multicolumn{2}{|l|}{ Group D (n=40) } & \multicolumn{2}{l|}{ Group S (n=40) } & "t” & "p" \\
\hline & Mean & SD & Mean & SD & & \\
\hline $\begin{array}{l}\text { Duration of } \\
\text { Analgesia (in hour) }\end{array}$ & $9.35+3.635$ & 3.634 & $2.93+1.347$ & 1.347 & 10.484 & 0.000 \\
\hline
\end{tabular}

Duration of analgesia( in Hours)

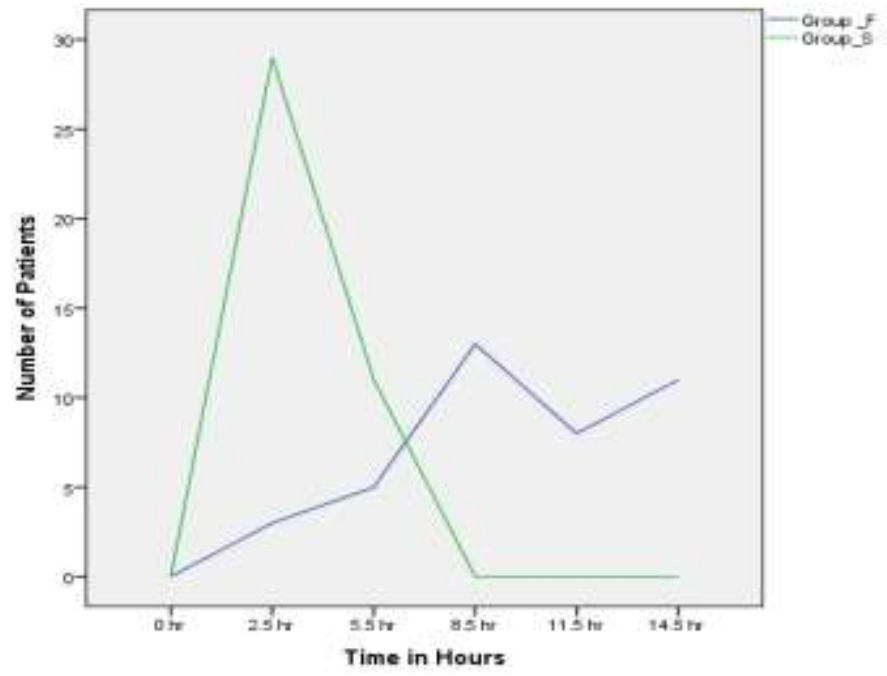

Hypotention was the most common complication in group D observed in 7 patients $(n=7 / 40)(17.5 \%)$ $(\mathrm{p}=)$. Five patients in group $\mathrm{D}(12.5 \%)$ had brdycardia while only one patient in group S had bradycardia. Two patients in group S had urinary retention and were catheterized. There was no complaint of headache , nausea, vomiting, shivering or respiratory depression in any of the study groups.

\section{Discussion}

Recent trends for gynecological surgeries show increased accptence of regional anesthesia. The mechanism by which intrathecal $\alpha_{2}$ adrenoceptor agonist prolong the onset and sensory block of local anesthetics is speculative. It may be an additive or synergistic effect secondary to the different mechanisms of action the local anesthetics and intrathecal $\alpha_{2}$ adrenoceptor agonist. Local anesthetics act by blocking sodium channels, $\alpha_{2}$ adrenoceptor agonist act by binding to the presynaptic C-fibres and postsynaptic dorsal horn neurons. They produce analgesia by depressing release of $\mathrm{C}$-fibre transmitters and by hyperpolarization of postsynaptic dorsal horn neurons. The complementary action of local anesthetics and $\alpha_{2}$ adrenoceptor agonist accounts for their profound analgesic properties. The prolongation of the motor block of spinal anesthetics may be the result of binding of to the motor neurons in the dorsal horn.

Dexmedetomidine is eight times more specific and highly selective $\alpha_{2}$ adrenoceptor agonist compared to clonidine ,thereby making it a safe adjunct in different clinical applications. Various authors has evaluated Dexmedetomidine as an epidural adjunct and found that it prolong the sensory and motor block duration time and postoperative analgesia without any additional morbidity. Clinical studies exhibits potentiation of neuraxial local anesthetics and decrease in intraoperative anesthetic requirement with prevention of intraoperative awareness, better postoperative analgesia when epidural or caudal

DOI: 10.9790/0853-150762329 $\quad$ www.iosrjournals.org $\quad 26 \mid$ Page


dexmedetomidine was used in conjunction with general anesthesia ${ }^{29-31}$. In this study we have used $5 \mu \mathrm{g}$ Dexmedetomidine which is based on previous human studies wherein no neurotoxic effects have been observed $^{18,19,27}$. Kanazi et al. foun that $3 \mu \mathrm{g}$ dexmedetomidine or $30 \mu \mathrm{g}$ clonidine added to $13 \mathrm{mg}$ spinal bupivacaine produced same duration of sensory and motor block with minimal side effects in urological surgical patients.

Mean time of onset of sensory block was faster in group D (4.65+0.976 min) compared to group S $(6.475+1.396 \mathrm{~min})$ in this study similar to that of Aliye Esmaoglu,Sumeyra Turk,Adnan Bayram et $\mathrm{al}^{21}$.(2013), Ahmed Soby Basuni, Hoda Alsaid Ahmed Ezz et $a^{24}{ }^{24}$ (2014) and Sherif A Abdelhamid et $a^{23}$.(2013). The maximum upper level of sensory block attained was $T_{6}$ in both the groups. Thus the mean value of upper level of sensory block was comparable in both the groups. Vania Kanvee and Gadhvi Rina et $\mathrm{al}^{22}$. studied comparative evaluation of dexmedetomidine and clonidine as an adjunct with intrathecal isobaric levobupivacaine in spinal anesthesia stated that there is no difference in the time of onset of sensory and motor block. Kim JE and Kim NY et $\mathrm{al}^{25}$. observed effect of intrathecal dexmedetomidine on low dose bupivacaine spinal anesthesia in elderly patients undergoing transurethral prostectomy found that it produced fast onset of sensory and motor block.

Duration of analgesia ( the time interval from subarachnoid block to first request of analgesic in postoperative period) was significantly prolonged in group $\mathrm{D}$ ( $561.0 \mathrm{~min}$ ) compared to group $\mathrm{S}$ ( $175.80 \mathrm{~min}$ ). We noted significantly delayed requirement of rescue analgesic and significantly reduced $24 \mathrm{hr}$. analgesic requirement with $5 \mu$ gdexmedetomidine when compared to group S. Prolonged perioperative analgesia after coadministration of dexmedetomidine and levobupivacaine can be explained by the complementary action of local anesthetics and $\alpha_{2}$ adrenoceptor agonist . Aliye Esmaoglu and Sumeyra et al. ${ }^{21}(2013)$ studied the effect of dexmedetomidine added to spinal levobupivacaine for transurethral endoscopic surgery and observed that the combined use of $3 \mu \mathrm{g}$ dexmedetomidine and levobupivacaine in spinal anesthesia prolongs sensory and motor block duration .Vania Kanvee and Gadhvi Rina et al ${ }^{22}(2015)$ did comparative evaluation of dexmedetomidine and clonidine as an adjunct with intrathecal levobupivacaine in spinal anesthesia found that intrathecal dexmedetomidine with isobaric levobupivacaine significantly prolongs sensory and motor block and postoperative analgesia as compared to clonidine. Kim et al. ${ }^{25}$ also stated that dexmedetomidine $3 \mu \mathrm{g}$ when added to intrathecal bupivacaine prolonged postoperative analgesia.

Dexmedetomidine evokes a biphasic blood pressure response. A short hypertensive phase and subsequent hypotension. The two phases are considered to be mediated by two different $\alpha 2$-AR subtypes; the $\alpha$ 2B In our study 7(17.5\%)patients developed hypotention in the group D versus $3(7.5 \%)$ in group $\mathrm{S}$ and this was managed by $\mathrm{i} / \mathrm{v}$ inj.ephedrine and i.v. fluids. Thus group D patients were haemodynamically less stable compared to group S. In the study of Gupta et.al ${ }^{17}$.(2011) hypotention was more in the dexmedetomidine group than in fentanyl group but it was not statistically significant. In agreement with our results,Kanazi et al ${ }^{18}$.showed insignificant effect of dexmedetomidine on mean blood pressure when added to intrathecal bupivacaine. Al.Mustafa et al ${ }^{19}$. using $5 \mu \mathrm{g}$, and $10 \mu \mathrm{g}$ dexmedetomidine ,found a dose dependent but still insignificant decrease on the mean blood pressure when compared to bupivacaine (control)group.

Patients who received intrathecal dexmedetomidine had more prolonged and intensified motor block compared to group S . Ahmed Sobhy Basuni and Hoda Alsaid Ahmed Ezz et al ${ }^{24}$.(2014) evaluated the effect of dexmedetomidine as supplement to low-dose levibupivacaine spinal anesthesia for knee arthroscopy found that it prolonged and intensified levobupivacaine sensory and motor block. Vania Kanvee and Gadhvi Rina et $\mathrm{al}^{22}$.(2015) did comparative evaluation of dexmedetomidine and clonidine as an adjunct with intrathecal levobupivacaine found that dexmedetomidine with isobaric levobupivacaine significantly prolongs sensory and motor block. Vidhi Mahendru et $\mathrm{al}^{20}$. (2013) studied the comparative evaluation intrathecal dexmedetomidine ,clonidine, and fentanyl as adjunct to hyperbaric bupivacaine for lower limb surgeries observed that intrathecal $5 \mu \mathrm{g}$ dexmedetomidine significantly prolonged the duration of motor block.

Ramila $\mathrm{H}$ Jamliya and Varun Deshmukh et $\mathrm{al}^{26}$. Observed the effect of adding dexmedetomidine to intathecal bupivacaine and found that $15 \mathrm{mg}$ hyperbaric bupivacaine supplemented with $5 \mu \mathrm{g}$ dexmedetomidine produces prolonged motor and sensory block.

The most significant side effect reported about the use of intrathecal $\alpha 2$ adrenoceptor agonist are bradycardia and hypotention. In our study these are not significant probably because we used small dose of intrathecal dexmedetomidine with high dose of local anesthetics. In group D, 7 (17.5\%) patients had bradycardia which responded to inj. Atropine sulphate $0.6 \mathrm{mg}$ i/v while bradycardia was observed in only one patient $(2.5 \%)$ in group S. Small dose of dexmedetomidine may also be responsible for minimal or no sedation in group D. No significant difference was observed in the sedation scores with patients in both the groups having score of 1 . There was no incidence of respiratory depression in patients in any of the groups. Lower VAS values $(<3)$ were observed in both the groups during the whole duration of the surgery.

This study reveals that when $5 \mu \mathrm{g}$ dexmedetomidine was added to isobaric levobupivacaine $15 \mathrm{mg}$ the combination leads to faster onset, more intense sensory and motor blockade which is haemodynamically 
less stable. The duration of postoperative analgesia was significantly prolonged without any remarkable side effects.

Thus overall combined effect of intrathecal levobupivacaine and dexmedetomidine is superior over levobupivacaine alone.

\section{Acknowledgement}

It is our pleasure and privilege to acknowledge the institutional help and support we have received towards the fulfillment of our endeavour. The experience of working in this institution has been an enriching one in terms of experience gained and in terms of self -assessment and self-evaluation.

We extend our sincere thanks to Dr, D.S.Negi ; Senior Specialist and Head,Department of Anesthesiology, Dr. RMLC Hospital,,Lucknow for his unstinted support and cooperation.

We would like to thank all the surgeons for their motivation and kind support in allowing us to pursue our research work on their patients.

We would like to thank to all the O.T.Staff of Dr.RMLC Hospital ,Lucknow for their help and cooperation and to all the Patients who were part of this study.

\section{References}

[1]. McDonald SB, Liu SS, Kopacz DJ, Stephenson CA. Hyperbaric spinal ropivacainea: Comparison to bupivacaine in volunteers. Anesthesiology 1999;90:971-7.

[2]. Alley EA, Kopacz DJ, McDonald SB, Liu SS. Hyperbaric spinal levobupivacaine: A comparison to racemic bupivacaine in volunteers. Anesth Analg 2002;94:188-93.

[3]. Gautier PE, De Kock M, Van Steenberge A, Poth N, Lahaye-Goffart B, Fanard L, Hody JL. Intrathecal ropivacaine for ambulatory surgery: A comparison between intrathecal bupivacaine and ropivacaine for knee surgery. Anesthesiology 1999; 91: 1239-45.

[4]. Breebaart MB, Vercauteren MP, Hoffmann VL, Adriaensen HA.Urinary bladder scanning after day-case arthroscopy under spinal anaesthesia: Comparison between lidocaine, ropivacaine, and

[5]. levobupivacaine. Br J Anaesth 2003;90:309-13.

[6]. Cuvas O, Basar H, Yeggel A, Turkyilmaz E, Sunay MM.Spinal anesthesia for transurethral resection operations: Levobupivacaine with or without fentanyl. Midle East J Anesthesiol 2010;20:547-52.

[7]. Girgin NK, Gurbet A, Turker G, Bulut T, Demir S, Kilic N, et al. he combination of low-dose levobupivacaine and fentanyl for spinal anaesthesia in ambulatory inguinal herniorrhaphy. J Int Med Res 2008;36:1287-92.

[8]. Whiteside JB, Wildsmith JA. Spinal anaesthesia: An update. Contin Educ Anaesth Crit Care Pain. Crit Care Pain 2005;5:37-40.

[9]. Glaser C, Marhofer P, Zimpfer G, Heinz MT, Sitzwohl C,Kapral S, et al. Levobupivacaine versus racemic bupivacaine for spinal anesthesia. Anesth Analg 2002;94:194-8.

[10]. De Santiago J, Santos-Yglesias J, Giron J, Jimenez A,Errando CL. Low-dose, low-concentration levobupivacaine plus fentanyl selective spinal anesthesia for knee arthroscopy: A dose finding study. Anesth Analg 2011;112:477-80.

[11]. de Santiago J, Santos-Yglesias J, Giron J, Montes de Oca F,Jimenez A, Diaz P. Low-dose $3 \mathrm{mg}$ levobupivacaine plus 10 microg fentanyl selective spinal anesthesia for gynecological outpatient laparoscopy. Anesth Analg 2009;109:1456-61.

[12]. 11. Kaya M, Oztürk I, Tuncel G, Senel GO, Eskiçirak H, Kadioğullari N. A comparison of low dose hyperbaric

[13]. levobupivacaine and hypobaric levobupivacaine in unilateral spinal anaesthesia. Anaesth Intensive Care 2010;38:1002-7.

[14]. Onur O, Sibel AM, Mustafa A, Mehmet Y. Comparison of the effects of intrathecal different dosage of levobupivacaine in elective day-case arthroscopy of the knee. Middle East J Anesthsiol 2010;20:703-8.

[15]. Compagna R, Vigliotti G, Coretti G, Amato M, Aprea G,Puzziello A, et al. Comparative study between levobupivacaine and bupivacaine for hernia surgery in the elderly. BMC Surg 2012;1 2 (Suppl 1):S12.

[16]. Sagir O, Ozaslan S, Erduran M, Meric Y, Aslan I, Koroglu A. Comparison between intrathecal hyperbaric bupivacaine and levobupivacaine for ambulatory knee arthroscopy. World J Anesthesiol 2013;2:18-25.

[17]. Gori F, Corradetti F, Cerotto V, Peduto VA. Influence ofpositioning on plain levobupivacaine spinal anesthesia in cesarean section. Anesthesiol Res Pract 2010;2012.

[18]. Gupta R, Bogra J, Verma R, Kohli M, Kushwaha JK, Kumar S. Dexmedetomidine as an intrathecal adjuvant for postoperative analgesia. Indian J Anaesth 2011;55:347-51.

[19]. 17 . Gupta R, Verma R, Bogra J, Kohli M, Raman R, Kushwaha JK.A Comparative study of intrathecal dexmedetomidine and fentanyl as adjuvants to Bupivacaine. J Anaesthesiol Clin Pharmacol2011;27:339-43.

[20]. 18.Kanazi GE, Aouad MT, Jabbour-Khoury SI, Al Jazzar MD, Alameddine MM, Al-Yaman R, et al. Effect of low-dose dexmedetomidine or clonidine on the characteristics of bupivacaine spinal block. Acta Anaesth Scand 2006;50:222-7.

[21]. 19. Al-Mustafa MM, Abu-Halaweh SA, Aloweidi AS, Murshidi MM,Ammari BA, Awwad ZM, et al. Effect of dexmedetomidine addedto spinal bupivacaine for urological procedures. Saudi Med J2009;30:365-70.

[22]. 20. Vidhi Mahendru, Anurag Tewari et al. A comparison of intrathecal xmedetomidine, clonidine, and fentanyl as adjuvants to hyperbaric bupivacaine for lower limb surgery, India Journal of Anaesthesiology Clinical Pharmacology | October-December 2013 | Vol 29 | Issue 4

[23]. 21. Aliye Esmaoğlu1, Sumeyra Turk et al.The Effects of Dexmedetomidine Added to Spinal Levobupivacaine for Transurethral Endoscopic Surgery. Balkan Med J 2013; 30: 186-90 • DOI: 10.5152/balkanmedj.2013.7082

[24]. 22. Vania Kanvee, Gadhvi Rina,et al. A Comparative Evaluation ofDexmedetomidine and Clonidine as an Adjunct with Intrathecal Inj. Levobupivacaine in Spinal Anaesthesia .J Res Med Den Sci. 2015; 3(1): 12-16

[25]. 23.Sherif A Abdelhamid and Mohamed H El-lakany: Intrathecal dexmedetomidine :useful or not ;J Anesh Clin Res 2013,49

[26]. 24. Ahmed Sobhy Basuni and Hoda Alsaid Ahmed Ezz:Dexmedetomidine as supplement to low dose levobupivacaine spinal anesthesia for knee arthroscopy; Egyption Journal of Anesthesia;2014,149-153.

[27]. 25. Kim JE and Kim NY et al. Effect of intrathecal demedetomidine on low dose bupivacaine spinal anesthesia in elderly patients undergoing transurethral prostectomy:Bio Pharm Bull,2013;36(6):959-65. 
[28]. 26. Ramila H Jamliya and Varun Deshmukh et al. : Effect of adding dexmedetomidine in intrathecal bupivacaine versus intathecal bupivacaine alone on spinal block characreristics in orthopaedic lower limb procedures;RJ of Pharm,Biological and Chemical Sciences 2013:4;1;1340.

[29]. 27. Al Ghanem SM, Massad IM, Al-Mustafa MM, Al-Zaben KR,Qudaisat IY, Qatawneh AM, et al. Effect of adding dexmedetomidine versus fentanyl to intrathecal bupivacaine on spinal blockcharacteristics in gynecological procedures: A double blind controlled study. Am J Appl Sci 2009;6:882-7.

[30]. 28. Elia N, Culebras X, Mazza C, Schiffer E, Tramer MR. Clonidine as an adjuvant to intrathecal local anesthetics for surgery: Systematic review of randomized trials. Reg Anesth Pain Med 2008;33:159-67.

[31]. 29. Grewal A. Dexmedetomidine: New avenues. J Anaesthesiol Clin Pharmacol 2011;27:297-302.

[32]. 30. Mantz J, Josserand J, Hamada S. Dexmedetomidine: New insights.Eur J Anaesthesiol 2011;8:3-6.

[33]. 31. Elhakim M, Abdelhamid D, Abdelfattach H, Magdy H, Elsayed A, Elshafei M. Effect of epidural dexmedetomidine on intraoperative awareness and post-operative pain after one-lung ventilation. Acta

[34]. Anaesthesiol Scand 2010;54:703-9.

[35]. 32. Saadawy I, Boker A, Elshahawy MA, Almazrooa A, Melibary S, Abdellatif AA, et al. Effect of dexmedetomidine on the characteristics of bupivacaine in a caudal block in pediatrics. Acta Anaesthesiol

[36]. Scand 2009;53:251-6.

[37]. 33. El-Hennawy AM, Abd-Elwahab AM, Abd-Elmaksoud AM, El-Ozairy HS, Boulis SR. Addition of clonidine or dexmedetomidine to bupivacaine prolongs caudal analgesia in children. Br J Anaesth 2009;103:268-74.

\section{Conflicts Of Interest}

The authors declare that they have no conflicts of interest with the research presented in this article. 